\title{
Immer dabei
}

Als der Mobilfunk eingeführt wurde, waren die aktentaschengroßen Telefone noch echte Hingucker. Benutzt wurden sie von recht wenigen. So wenigen, dass es bei der Einführung des D2-Netzes Stimmen gab, die daran zweifelten, dass sich das überhaupt lohne, der Bedarf sei zu gering. Heute ist der Besitz eines Handys so selbstverständlich wie das Vorhandensein einer Postanschrift. Die ständige Erreichbarkeit nahezu aller ist Alltag geworden. Aber damit hat die Entwicklung noch längst nicht ihr Ende gefunden. Mit den sogenannten Smartphones trägt inzwischen ein Großteil der Menschen einen Taschencomputer mit sich herum, der weit mehr kann, als bloße Telefonie oder SMS.

Im privaten und beruflichen Kontext haben diese neuen Möglichkeiten unser Leben verändert. Vieles lässt sich von unterwegs erledigen, schnell auf eine Mail antworten oder einen Termin bestätigen etwa. Das erhöht einerseits die Produktivität, löst aber auch die Grenzen zwischen Privat- und Berufsleben auf - manche bringt das in Schwierigkeiten. Aber nicht nur auf der persönlichen Ebene hat das Thema zwei Seiten, auch technologisch ergeben sich neue Herausforderungen. An erster Stelle steht dabei, dass die neuen Geräte immer auch neue Angriffspunkte für die Sicherheit von Unternehmen darstellen. Wie immer gilt es abzuwägen zwischen Chancen und Risiken.

Herzliche Grüße

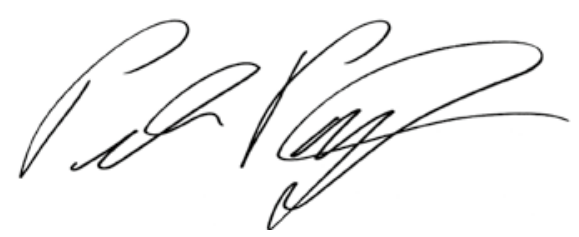

Peter Pagel

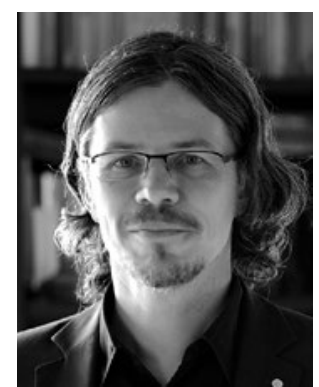

Peter Pagel

Chefredakteur 